\title{
PROGRESS ON THE NEW HIGH POWER 200 MHZ RF SYSTEM FOR THE LANSCE DTL*
}

\author{
John T. M. Lyles ${ }^{\#}$, Donald C. Clark, Jerry L. Davis, Carl C. Friedrichs, Jr. ${ }^{\circledR}$, Rodney C. McCrady, \\ LANL, Los Alamos, NM 87545 USA
}

\begin{abstract}
The Los Alamos Neutron Science Center (LANSCE) linac accelerates up to $1 \mathrm{~mA}$ average of proton current for various applications, including the short pulse spallation neutron source, proton radiography, isotope production and neutron research. Long beam pulses at high current put extreme demands on the drift tube linac (DTL) RF power amplifiers, which were originally installed in 1972. A new RF power system is being developed for increased peak power with higher duty factor. The final power amplifiers use a THALES TH628 Diacrode ${ }^{\circledR}$ and will not require the large anode modulators used in the present system. The RF amplitude control will be introduced at a low level in the power chain. When completed, the new system will reduce the number of electron power tubes from twenty-four to seven in the RF plant for the 100 $\mathrm{MeV}$ DTL. Details of the EM field models, the mechanical layout, prototype construction techniques, RF tests, and system considerations will be discussed.
\end{abstract}

\section{DTL RF SYSTEM LIMITATIONS}

The LANSCE proton linac provides an $800 \mathrm{MeV}$ direct $\mathrm{H}^{+}$proton beam, and also injects $\mathrm{H}^{-}$to a proton storage ring for charge accumulation for the spallation neutron source. Accelerating beams for various applications often requires high peak and average power from the 201.25 MHz DTL RF system. Three Burle 7835 triode final power amplifiers (FPA) provide as much as three megawatts (MW) each at $12 \%$ duty factor (DF) for three Alvarez tanks. A Burle 4616 tetrode intermediate power amplifier (IPA) drives each FPA. A similar system drives the first $4.6 \mathrm{MeV}$ tank at $400 \mathrm{~kW}$.

These amplifiers have been in service for nearly thirty years. The FPA triode must be operated within a pressure vessel operating with 2.4 bar dry air to maintain voltage standoff. Because of the high average power, the pressurized air must be circulated and cooled to remove heat from the tube seals and blocking capacitors inside the FPA. The triode has 96 parallel filament strands requiring a 7000 Ampere DC filament power supply with watercooled cables. Replacement of the FPA tube takes approximately 16 hours due to the enormous pressure vessel that must be removed first.

Over the past eight years, significant improvements to the systems have reduced the number of electron power tubes in the DTL RF plant from fifty-two to twenty-four

\footnotetext{
* Work supported by the United States Department of

Energy under contract number W-7405-ENG-36.

\# jtml@1anl.gov

@ retired
}

[1]. A previous report tabulated future RF power needs, the largest being 3.6 MW for a $21 \mathrm{~mA}$ beam in DTL tank two [2]. Both peak current and beam DF are restricted, in part, by the maximum dissipation ratings of the present triodes. A new IPA and FPA are being tested as replacements for the original amplifiers. With only seven power tubes, this new DTL RF plant can deliver both peak power and high duty factor, with lower AC mains power and cooling requirements.

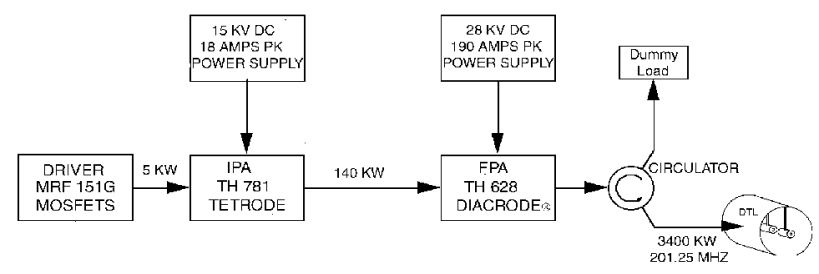

Figure 1: Block Diagram of New Amplifier Chain

\section{DESIGN OF NEW RF SYSTEM}

\subsection{Intermediate Power Amplifier}

The THALES TH781 was chosen as a modern tetrode along with a THALES-developed cavity amplifier to provide 14 - $15 \mathrm{~dB}$ power gain to cathode-drive the FPA at $140 \mathrm{~kW}$. This compact linear amplifier has been specified to operate at up to $500 \mathrm{~kW}$ peak at low duty factor. It may be used alone with a circulator for the first DTL tank, in place of the existing tetrode/triode chain.

\subsection{Final Power Amplifier}

The TH628 Diacrode ${ }^{\circledR}$ is utilized in a new FPA being developed in-house at LANSCE. This four element double-ended tube uses pyrolytic graphite grids, a thoriated-tungsten mesh cathode, and a multiphase-cooled anode rated to dissipate $1.5 \mathrm{MW}$ [3]. The new FPA operates as a class $\mathrm{AB}_{2}$ linear amplifier, eliminating the need for an anode voltage modulator (see fig.1). Power control for tank fields will be accomplished by adjusting the low-level RF drive to the preamplifier stage. The $9 \mathrm{kV}$ overhead of the old plate modulator will be eliminated as the tube is pulsed into conduction with control grid bias. This will allow lower voltage operation of our capacitor banks. The mesh filament current is only $14 \%$ of the triode filament current.

Thomson Tubes Electroniques (now THALES) first proposed to develop a $200 \mathrm{MHz}$ tube capable of delivering $3 \mathrm{MW}$ peak and $600 \mathrm{~kW}$ average power to Los Alamos in 1989. The real performance today is much better than what was expected then. It has been tested at 3 $\mathrm{MW}$ and at $1 \mathrm{MW} \mathrm{CW}$ at $20 \% \mathrm{DF}$. The tube has also demonstrated 4.1 MW output at $30 \mathrm{kV}$ DC anode voltage 
when pulsed at $5 \%$ DF. At lower duty it has produced 4.5 MW, limited by the THALES test set power supply.

The double-ended RF circuit doubles the average power capability of a conventional gridded tube by increasing the active length inside the tube to nearly $\lambda / 8$. The so-called "dead head" region above the active region is replaced with seals and connections to a second external cavity circuit. This concept is not new, having been utilized in some RCA super power tubes before 1958 [4]. The 7835 triode used in our present FPA operates in this fashion. In the Diacrode ${ }^{\circledR}$, the anode/screen circuit is brought out at each end of the tube, while the input cathode/grid circuit is folded back inside the center of the filament structure and terminates twice at the bottom of the tube. Both ends can be connected to a line circuit, or capacitively loaded as needed to center the drive voltage maximum along the active zone.

\subsection{Analysis and Design of FPA}

A $28 \mathrm{kV}$ quiescent point was selected from the TH628 DC curves to verify adequate emission (figure 2). With 3.6 MW peak RF, the load line swings down to $4.5 \mathrm{kV}$ where the anode current is 650 Amperes. The total cathode current is the sum of this plus the screen and control grid currents, and is within the tube ratings. With a $23.5 \mathrm{kV}$ peak and $301 \mathrm{~A}$ peak fundamental current, the optimal load, Rp, is 78 Ohms. In this example the cavity transforms the $50 \mathrm{Ohm}$ output line impedance to the anode $\mathrm{Rp}$ at resonance. The lower main line is tuned $3 / 4 \lambda$ long while the upper slave cavity is $1 / 4 \lambda$ long. The input circuit is tuned $3 / 4 \lambda$ to center a voltage maximum in the cathode/grid space of the tube.

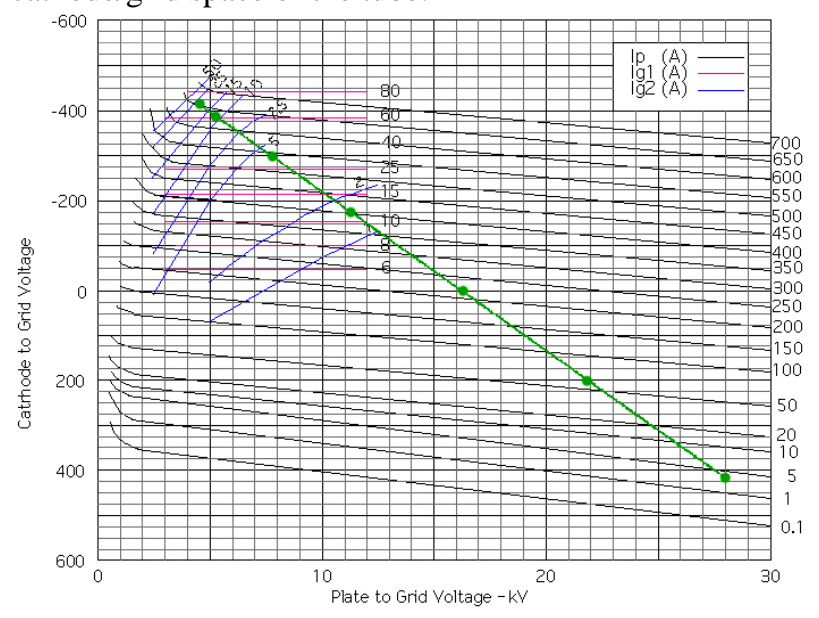

Constant Current Curves $-\mathrm{TH} 628$ (vg 2=1.5 kv)

Figure 2: 3.6 MW Load Line

Two independent codes were utilized to develop this cavity amplifier. SUPERFISH 6 was used to compute the electric and magnetic fields from the geometry of the cavity and the tube internal dimensions. A portion of the plot of the field distribution across one half of the output cavity is shown adjacent to the amplifier in figure 3 . There are two voltage maximums, one centered in the active region of the Diacrode ${ }^{\circledR}$, and the other in a wide portion of the cavity above the coupling loop. There is low RF voltage stress at the ceramic seals of the tube.

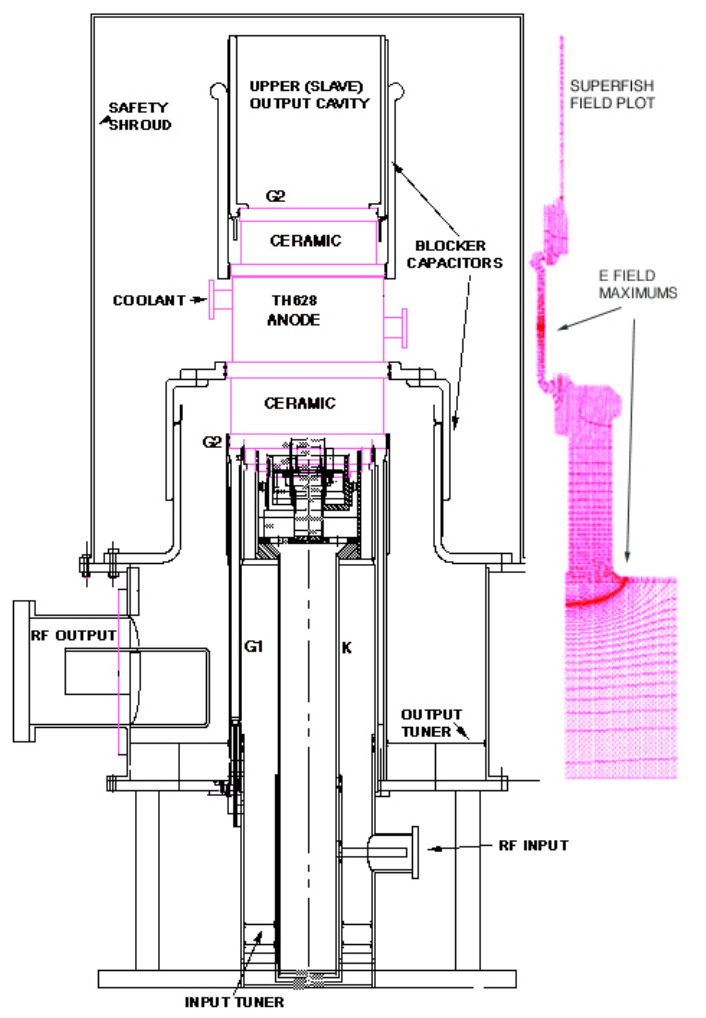

Figure 3: Diagram of Amplifier and Field Plot

Fortran code developed by C. Friedrichs was used to solve for the loading of the TH628 input and output regions by calculating transmission line admittances from the tube to the tuning short. Radial transmission lines were calculated [5] and small discontinuity capacitances were added to account for major step changes in the conductor diameters [6]. The results were very similar to the Superfish predictions. Table 1 lists a comparison of line impedances from nine points along the longitudinal axis of the input cavity. The ratio of $\mathrm{E}$ to $\mathrm{H}$ from Superfish is nearly constant across the radius of the dielectric (air or vacuum) at each point. To convert the Superfish field values to impedance, $\mathrm{Z}$ :

$$
|\mathrm{Z}|=\frac{|E|}{|H|} \times \frac{\ln \frac{R_{o}}{R_{i}}}{2 \pi}
$$

This value is compared to the impedance calculated from the Fortran transmission line code at the same locations. Agreement is very good. Similar agreement was observed for the output calculations.

The input port has a transformer to a $35 \mathrm{Ohm}$ direct feed point to keep the $79 \mathrm{~mm}$ (3.125 inch) coaxial connection below the frame. In this way the input port remains below the output circuit, not reentrant as is often the case. This simplifies the mechanical design. A watercooled loop has been designed to drive the output $232 \mathrm{~mm}$ (9.166 inch) pressurized coaxial line. A transition to 355 $\mathrm{mm}$ (14 inch) line immediately follows. Because a voltage 
maxima is just below the step in outside diameter (fig. 3), an alternative electrostatic coupling plate has also been considered. A loop has the mechanical advantage of simple water cooling through the grounded side, and can be rotated easily with contact fingers once the flange is loosened. This can be used to optimize coupling at the various operating points for each DTL.

Table 1: Superfish and Fortran Impedances

\begin{tabular}{|c|c|c|}
\hline $\begin{array}{c}|\mathbf{E} / \mathbf{H}| \\
\text { field ratio }\end{array}$ & $\begin{array}{c}\text { Calc. }|\mathbf{Z}| \text { from } \\
\text { Superfish }\end{array}$ & $\begin{array}{c}|\mathbf{Z}| \text { from } \\
\text { Fortran }\end{array}$ \\
\hline $\mathrm{V} / \mathrm{m} / \mathrm{A} / \mathrm{m}$ & $\mathrm{V} / \mathrm{A}=\Omega$ & $\Omega$ \\
\hline 1396.35 & 4.361 & 4.360 \\
\hline 377.58 & 2.438 & 2.446 \\
\hline 186.74 & 1.533 & 1.541 \\
\hline 13.89 & 0.325 & 0.325 \\
\hline 156.166 & 3.985 & 3.985 \\
\hline 425.68 & 15.804 & 15.869 \\
\hline 1045.17 & 132.332 & 132.332 \\
\hline 407.74 & 48.763 & 48.937 \\
\hline 138.85 & 14.728 & 14.850 \\
\hline
\end{tabular}

The amplifier has been constructed and is being coldtested at the time of this report (see figure 5). The input and output circuits were swept and tuned to produce the plot of figure 4 . The input match should improve when cathode current is flowing in the cathode-driven arrangement as it loads the input. These measurements were made with solid metal output cavities, without the anode/screen blocker capacitors inserted. They will be now be manufactured with shrink-fit fluoropolymer dielectric sleeves similar to those in the original FPA.

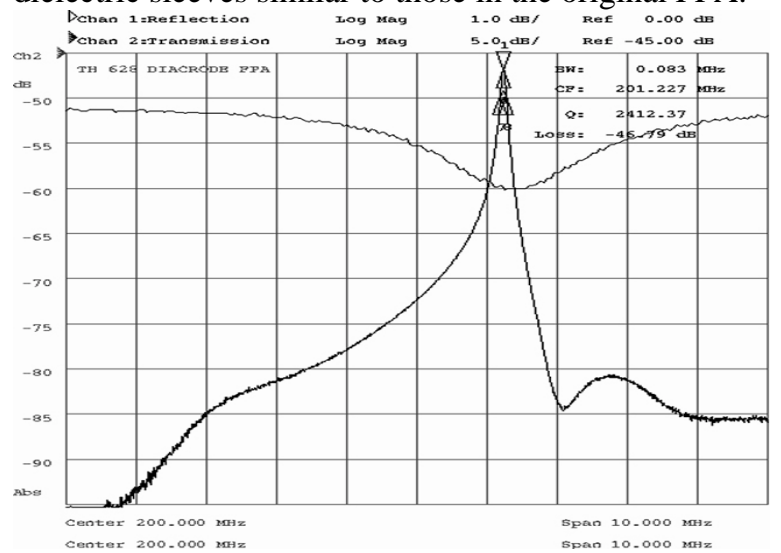

Fig. 4: Input Reflection \& Transmission [Log Magnitude]

\section{COAXIAL CIRCULATOR}

The new power amplifiers will each drive a circulator before the $355 \mathrm{~mm}$ (14 inch) feedline to the linac. Advanced Ferrite Technology (AFT) has developed a large coaxial Y junction circulator for this application. It is designed to withstand the peak and average power at the Los Alamos altitude. This manufacturer has supplied similar coaxial circulators to the MIT/Lincoln Lab Altair radar system. A water load and directional couplers finish the complement of high power transmission hardware to be installed at each upgraded RF station. Testing at AFT is expected in September of 2001 with delivery of the first unit following. The test set for the existing 7835 FPA will be used for full power testing of each new circulator.

\section{PROJECT SUMMARY}

The THALES IPA cavity and TH781 tetrode have been received and are being assembled in an enclosure with filament power and cooling. The prototype FPA cavity has been assembled for the TH628 Diacrode ${ }^{\circledR}$. Cold testing has proven that it tunes as the codes predicted. Work is underway on the anode/screen DC blocker capacitors, cooling hose passageways, the upper slave cavity, and parasitic mode suppressors. The DC power supplies are installed for a new test station. RF power testing is planned to begin in the fall. Gerry Bolme, Sean Newmann, Steve Archuletta, Dave Keffeler, and William Roybal have assisted the authors on this project.

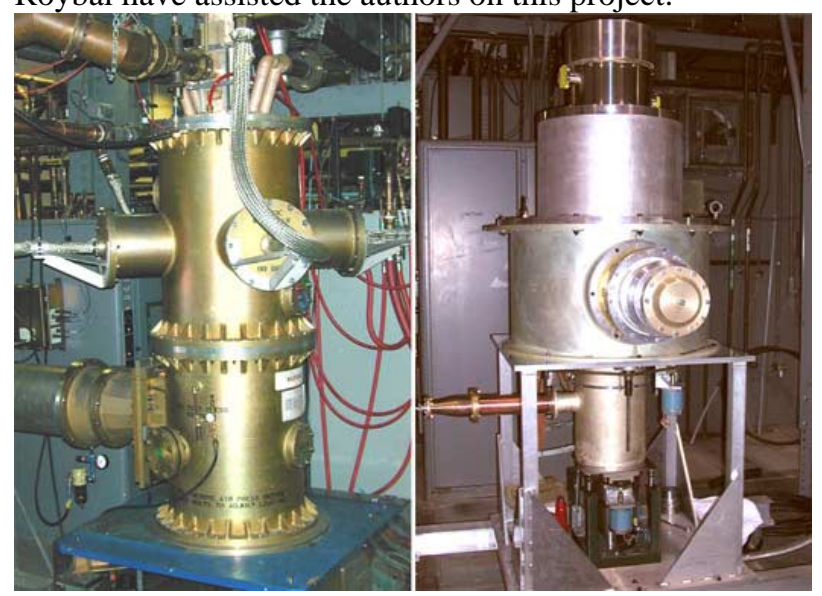

Figure 5: Original and New FPA (Not to Scale)

\section{REFERENCES}

[1] J. T. M. Lyles, C. C. Friedrichs, "LANSCE 201.25 MHZ Drift Tube Linac RF Power Status," Proc. International Linac Conference, Geneva, 1996.

[2] J. Lyles, C. Friedrichs, M. Lynch, "New High Power 200 MHz RF System for the LANSCE Drift Tube Linac," Proc. XIX International Linac Conference, Chicago, 1998, pp. 231-233.

[3] G. Clerc, JP. Ichac, C. Robert, "A New Generation of Gridded Tubes for Higher Power and Higher Frequencies," Proc. Particle Accelerator Conference, Vancouver, 1997, pp. 2899-2901.

[4] M. Hoover, "Advances in the Techniques and Applications of Very-High-Power Grid-Controlled Tubes," Proc. Int. Convention on Microwave Valves, 1958, IEE Paper No. 2752R.

[5] S. Ramo, J. Whinnery, T. Duzer, "Fields and Waves in Communication Electronics," New York, John Wiley \& Sons, 1965, pp. 453-457.

[6] T. Moreno, "Microwave Transmission Design Data," New York, McGraw Hill, 1948, pp. 96-101. 